\title{
PENGARUH USIA DAN LAMA KERJA BIDAN TERHADAP KESADARAN SOSIAL BIDAN DALAM PEMBERIAN TABLET FE PADA IBU HAMIL
}

\author{
EffectofMidwife's Age andLengthofEmployment Towards Social \\ AwarenessofMidwifeinFe Tablets Administrationfor Pregnant Women
}

\author{
Agus Aan Adriansyah \\ Staf Pengajar Program Studi S1 Ilmu Kesehatan Masyarakat \\ Fakultas Kesehatan, Universitas Nahdlatul Ulama Surabaya \\ Email: aan.naufal87@unusa.ac.id or aan naufal87@yahoo.com. Hp: 081335770075
}

\begin{abstract}
Coverage of Fe tablets during antenatal care visit from 2011-2013 in Public Health Centers in Surabaya was still low with an average percentage of $9.29 \%$ and $16.27 \%$. The study aim to analyze effect of midwife's age and length of employment towards social awareness of midwife in Fe tablets administration for pregnant women in Public Health Centers in Surabaya.This research was an analytic observational study and a cross sectional approach. The research location was in all Public Health Centers in Surabaya. The samples as many as 65 midwives were taken using multistage random cluster sampling technique from 62 Public Health Centers representing every region in Surabaya. The data obtained were analyzed by using Ordinal Logistic Regression technique.The results showed that the older midwives (more than 36 years) have a better social awareness since they have had experience in interacting with the social world. Midwives who work longer (more than 10 years) tend to have better social awareness. The conclusion of this study is that the midwife's age and length of employment are closely towards social awareness of midwife.
\end{abstract}

Keyword: Social Awareness, Midwife, Fe tablets

\begin{abstract}
Abstrak
Cakupan Tablet Fe selama kunjungan antenatal dari periode tahun 2011-2013 di Puskesmas di Surabaya masih terbilang rendah dengan persentase rata-rata 9,29\% (Fe 1) dan $16,27 \%$ (Fe 3). Penelitian ini bertujuan untuk menganalisis pengaruh usia bidan dan lama kerja bidan terhadap kesadaran sosial yang dimiliki bidan dalam pemberian tablet Fe untuk ibu hamil di Puskesmas di Surabaya.Penelitian ini merupakan penelitian observasional analitik dengan menggunakan pendekatan cross sectional. Lokasi penelitian berada di wilayah Puskesmas kota Surabaya. Sampel penelitian sebesar 65 bidan yang diambil dengan menggunakan teknik multistage random cluster sampling dari 62 Puskesmas yang mewakili setiap wilayah di Surabaya. Data yang diperoleh kemudian dianalisis dengan teknik Regresi Logistik Ordinal.Hasil penelitian menunjukkan bahwa bidan yang berusia lebih matang (lebih dari 36 tahun) memiliki kesadaran sosial yang lebih baik karena mereka memiliki pengalaman dalam berinteraksi dengan dunia sosial. Bidan yang bekerja lebih lama (lebih dari 10 tahun) cenderung memiliki kesadaran sosial Agus Aan Adriansyah adalah Staf Pengajar Program Studi S1 Ilmu Kesehatan Masyarakat Fakultas Kesehatan Universitas Nahdlatul Ulama Surabaya
\end{abstract}


yang lebih baik.Usia bidan dan lama kerja bidan berpengaruh signifikan terhadap kesadaran sosial bidan.

Kata Kunci:Kesadaran Sosial. Bidan, Tablet Fe

\section{PENDAHULUAN}

World Health Organization (WHO) melaporkan bahwa prevalensi ibu hamil yang mengalami defisiensi besi sekitar 35$75 \%$, serta semakin meningkat seiring dengan pertambahan usia kehamilan. Anemia defisiensi zat besi lebih cenderung berlangsung di negara yang sedang berkembang daripada negara yang sudah maju. Lebih kurang 36\% (atau sekitar 1,4 milyar orang) dari perkiraan populasi 3,8 milyar orang di negara berkembang menderita anemia jenis ini, sedangkan prevalensi di negara maju hanya sekitar 8\% (atau kira-kira 100 juta orang) dari perkiraan populasi 1,2 milyar orang.

Di Indonesia, prevalensi anemia pada kehamilan masih tinggi. Sebanyak $40,1 \%$ diantaranya adalah ibu hamil dengan jenis anemia kekurangan zat besi ${ }^{1}$. Dalam Rencana Pembangunan Jangka Menengah Nasional (RPJMN) bidang Kesehatan 2010-2014 telah ditetapkan salah satu sasaran pembangunan yang akan dicapai adalah menurunkan prevalensi gizi kurang setinggi-tingginya $15 \%$ dan menurunkan prevalensi balita pendek menjadi setinggi-tingginya $32 \%$. Untuk mencapai sasaran tersebut, dalam Rencana Aksi Pembinaan Gizi Masyarakat telah ditetapkan 8 indikator kinerja, yang salah satunya adalah persentase ibu hamil mendapatkan tablet zat besi $(\mathrm{Fe})^{2}$.

Anemia gizi besi pada ibu hamil masih menjadi masalah kesehatan masyarakat. Banyak wanita Indonesia tidak memperdulikan atau kurang memahami aspek kekurangan zat besi. Pemberian tablet $\mathrm{Fe}$ merupakan salah satu upaya penting dalam mencegah dan menanggu- langi anemia zat besi ${ }^{3}$. Manfaat tablet $\mathrm{Fe}$ selama kehamilan sangat penting dalam membantu proses pembentukan sel darah merah sehingga mencegah kekurangan darah merah, dan dapat menurunkan Angka Kematian Ibu (AKI). Disamping itu, manfaat lainnya adalah meningkatkan asupan nutrisi bagi janin dan mencegah terjadinya perdarahan pada saat persalinan.

Konsumsi tablet Fe oleh ibu hamil juga tidak dapat dipisahkan oleh sikap dan upaya dari petugas kesehatan terutama bidan. Bidan selalu berhubungan dengan ibu hamil di wilayah kerjanya. Bidan berkewajiban mengajak ibu hamil untuk selalu menjaga kondisi kandungannya dan menganjurkan melakukan pemeriksaan kehamilan secara rutin (K1-K4) dengan salah satu pelayanannya adalah pemberian tablet Fe. Cakupan administrasi Fe dari tahun 2011 sampai 2013 di beberapa Puskesmas di Surabaya belum mencapai target. Cakupan rata-rata Fe yang tidak mencapai target 2011 sampai 2013 adalah 21 puskesmas $(34,61 \%)$.

Kepatuhan mengkonsumsi tablet Fe dapat dipengaruhi oleh rendahnya kepatuhan konsumsi tablet $\mathrm{Fe}$ oleh ibu hamil akibat dari penyuluhan yang kurang adekuat dari petugas kesehatan terutama bidan dan dukungan keluarga yang tidak baik sehingga ibu hamil tidak patuh menkonsumsi tablet $\mathrm{Fe}^{3}$. Keberhasilan konsumsi Fe oleh ibu hamil tidak lepas dari karakter, sikap dan usaha petugas kesehatan khususnya bidan. Bidan selalu dikaitkan dengan wanita hamil di wilayah kerjanya. Oleh karena itu, bidan harus memiliki karakter, keterampilan, kompetensi dan pengalaman dalam 
melayani ibu hamil. Peran bidan sebagai pelaksana program diharapkan dapat meningkatkan pengetahuan ibu hamil melalui penyuluhan ${ }^{3}$. Bidan perlu memiliki karakter kesadaran sosial agar dapat dijadikan sebagai pondasi dalam membangun hubungan dengan lingkungan sosial di sekitarnya.

Pemilihan karakteristik bidan dalam umur dan lama kerja terkait erat dengan kemampuan sosial, seperti yang dikemukakan oleh Goleman ${ }^{4}$ bahwa emotional intelligence bukan kecerdasan warisan biologis, tetapi tumbuh dan berkembang melalui proses belajar seumur hidup yang didapat melalui pengalaman diri sendiri maupun orang lain.Oleh sebab itu, bidan harus memiliki keahlian dan kompetensi yang baik serta berpengalaman dalam melayani ibu hamil. Bidan harus memiliki kemampuan berinteraksi secara sosial dengan baik. Sehingga seorang bidan

\section{METODE PENELITIAN}

Jenis Penelitian ini adalah penelitian observasional analitik yang dilakukan dengan menggunakan pendekatan cross sectional, karena pada saat pengumpulan data hanya dilakukan satu kali dalam satu waktu tertentu dan secara bersamaan terhadap variabel yang diteliti ${ }^{5}$. Populasi pada penelitian ini adalah bidan Puskesmas yang berjumlah 281, yang tersebar di 62 Puskesmas Kota Surabaya.

Sampel pada penelitian ini adalah sebagian bidan yang berada di Puskesmas Kota Surabaya yang menjadi responden dalam penelitian. Besar sampel yang dijadikan responden penelitian adalah sebesar 65 bidan dari 62 Puskesmas di Kota Surabaya. Teknik pengambilan sampel dilakukan dengan teknik multistage cluster random sampling dari sejumlah Puskesmas yang mewakili setiap wilayah di Kota Surabaya, mulai dari Surabaya Pusat, perlu memiliki kesadaran sosial, yaitu sebuah sikap yang mampu mengenali dan memahami emosi orang lain.

Masalah yang diteliti adalah rendahnya cakupan pemberian $\mathrm{Fe}$ dibandingkan dengan jumlah kunjungan antenatal pada 2011-2013 di Puskesmas di Surabaya dengan persentase rata-rata $16,27 \%$. Rendahnya cakupan administrasi Fe terkait erat dengan kemampuan yang dimiliki oleh petugas kesehatan seperti karakteristik bidan meliputi usia dan lama kerja sehingga berdmpak pada kesadaran sosial yang dimiliki. Tujuan dari penelitian ini adalah untuk menganalisis pengaruhusia dan lama kerja bidan dengan kesadaran sosial bidan dalam pemberian Fe kepada ibu hamil di Puskesmas Surabaya.

Surabaya Timur, Surabaya Barat, Surabaya Utara dan Surabaya Selatan.

Data penelitian merupakan data primer. Pengumpulan data dilakukan dengan mengacu pada penelitian lapangan (field research), dengan menggunakan alat bantu berupa instrumen kuesioner Analisis data dilakukan terhadap setiap variabel penelitian. Data yang telah diperoleh dianalisis dan interpretasikan untuk menguji hipotesis dengan menggunakan aplikasi komputer (software) statistik. Análisis yang dilakukan meliputi analisis univariabel bertujuan untuk mengetahui distribusi frekuensi dan proporsi dari variabel usia dan lama kerja bidan, serta kesadaran sosial bidan. Análisis selanjutnya adalah analisis bivariabel dilakukan untuk menilai pengaruh antara usia dan lama kerja terhadap kesadaran sosial bidan. Metode yang digunakan adalah dengan melakukan cross tabulasi silang antar variabel usia dan lama kerja bidan 
97 Jurnal IKESMA Volume 13 Nomor 2 September 2017

terhadap kesadaran sosial bidan. Análisis terakhir adalah Uji pengaruh yang dilakukan dengan menggunakan teknik Regresi Logistik Ordinal untuk mengetahuipengaruh antara usia dan lama kerja bidan terhadap kesadaran sosial bidan.

\section{HASIL DAN PEMBAHASAN \\ Usia Bidan}

Karakteristik bidan berdasarkan umur dalam penelitian di Puskesmas Kota Surabaya dapat dilihat padaTabel 1 . Berikut

ini.

Tabel 1. Karakteristik Bidan Berdasarkan Usia di Puskesmas Kota Surabaya

\begin{tabular}{ccccc}
\hline No. & & Usia Bidan & $\mathbf{n}$ & $\mathbf{\%}$ \\
\hline 1 & $\leq 25$ tahun & & 9 & 13,85 \\
\hline 2 & $26-35$ tahun & 33 & 50,77 \\
\hline 3 & $36-45$ tahun & 10 & 15,38 \\
\hline 4 & $46-55$ tahun & & 13 & 20,00 \\
\hline & & Total & 65 & 100,00 \\
\hline
\end{tabular}

Berdasarkan Tabel 1. dapat diperoleh informasi bahwa sebagian besar bidan termasuk dalam kategori umur 26-35 tahun dengan persentase 50,77\%. Kategori umur ini merupakan kelompok terbanyak yang sedang memberikan pelayanan pada Ibu hamil terkait pemberian tablet Fe. Disamping itu, kelompok umur tersebut merupakan kelompok pekerja dengan umur yang relatif masih sangat produktif.

Bidan dengan umur yang relatif masih produktif diharapkan mampu untuk terus memberikan pelayanan terbaik kepada ibu hamil. Senantiasa memotivasi dan memberikan semangat tidak kenal lelah saat memberikan pelayanan yang terbaik pada Ibu hamil khususnya pada layanan pemberian tablet Fe. Semakin banyak bidan yang tergolong dalam umur 26-35 tahun diharapkan semakin membuat pelayanan kepada ibu hamil lebih baik, berkualitas dan meningkatkan derajat kesehatan ibu hamil.Nitisemito ${ }^{6}$ menyatakan bahwa pegawai yang lebih muda cenderung mempunyai fisik yang kuat, sehingga diharapkan dapat bekerja keras.

\section{Lama Kerja Bidan}

Lama kerja dapat menggambarkan pengalaman seseorang dalam menguasai bidang tugasnya. Pada umumnya, petugas dengan pengalaman kerja yang banyak tidak memerlukan bimbingan dibandingkan dengan petugas yang pengalaman kerjanya sedikit.

Karakteristik bidan berdasarkan lama kerja dalam penelitian di Puskesmas Kota Surabaya dapat dilihat pada Tabel 2.

Tabel 2. Karakteristik Bidan Berdasarkan Lama Kerja di Puskesmas Kota Surabaya

\begin{tabular}{clcc}
\hline No. & \multicolumn{1}{c}{ Lama Kerja Bidan } & $\mathbf{n}$ & $\mathbf{\%}$ \\
\hline 1 & Dibawah 6 tahun & 26 & 40,00 \\
\hline 2 & 6-10 tahun & 13 & 20,00 \\
\hline 3 & Diatas 10 tahun & 26 & 40,00 \\
\hline \multicolumn{2}{r}{ Total } & 65 & 100,00 \\
\hline
\end{tabular}


Berdasarkan Tabel 2. dapat diperoleh informasi bahwa hampir sebagian besar bidan $(40,00 \%)$ merupakan petugas yang memiliki banyak pengalaman kerja dalam melayani Ibu hamil di Puskesmas khususnya pada pelayanan pemberian tablet Fe.

Bidan dalam penelitian ini sebagian besar merupakan petugas yang memiliki lama kerja lebih dari 10 tahun mengabdi dalam melayani Ibu hamil di Puskesmas khususnya pada pelayanan pemberian tablet Fe. Bekerja dengan waktu yang cukup lama di sebuah unit kerja dapat menjadikan banyak pengalaman kerja yang dapat dipetik. Diharapkan dengan semakin lama bidan bekerja di puskesmas maka bidan semakin berpengalaman sehingga mereka mampu memberikan bentuk pelayanan yang terbaik pada Ibu hamil khususnya pada layanan pemberian tablet Fe agar ibu hamil selalu terjamin pemenuhan kebutuhan tablet $\mathrm{Fe}$ demi menjaga kondisi kesehatan kandungannya. Erawan ${ }^{7}$ menyatakan bahwa lama kerja terkait dengan pengalaman kerja.Hal ini berpengaruh terhadap motivasi kerja tenaga kerja bekerja.

Menurut Ranupendjaja \& Saud8, semakin lama seseorang bekerja pada suatu organisasi maka semakin berpengalaman orang tersebut sehingga kecakapan kerjanya semakin baik. Oleh sebab itu, bidan yang telah lama bekerja diharapkan memiliki kemampuan lebih baik dalam memberikan pelayanan pada ibu hamil terutama pemberian tablet Fe.

Umumnya bidan dengan pengalaman kerja yang lebih lama cenderung memiliki kesadaran sosial yang lebih baik. Dalam penelitian ini, lama kerja diatas 10 tahun memiliki hubungan dengan kesadaran sosial yang dimiliki bidan daripada mereka yang lama kerjanya dibawah 10 tahun. Hal ini didasari bahwa bidan dengan pengalaman lebih dalam melayani ibu hamil akan tumbuh dalam dirinya kesadaran sosial yang semakin baik. Kebiasaan yang bidan lakukan akan menjadi sebuah pem-belajaran untuk dapat meningkatkan kesadaran sosial yang dimiliki. Hal ini sejalan dengan teori Goleman yang menyatakan bahwa kesadaran sosial tumbuh dan berkembang sejalan semakin dipupuk dan diperkuatnya diri dalam waktu yang cukup ${ }^{10}$. Oleh sebab itu, dapat menjadi pertimbangan bila ingin menempatkan seorang petugas yang akan bertanggung jawab dalam hal pemberian pelayanan pada masyarakat untuk lebih memperhatikan lama masa kerja atau pengalaman kerja yang dimiliki oleh bidan karena dapat berkaitan dengan tingkat kesadaran sosial yang dimiliki.

\section{Kesadaran Sosial Bidan}

Gambaran umum kesadaran sosial bidan selengkapnya dapat dilihat sebagai berikut.

Tabel 3 Penilaian Kesadaran Sosial Bidan Secara Keselurahan di Puskesmas Kota Surabaya

\begin{tabular}{ccccc}
\hline No. & & Kesadaran Sosial & n & \% \\
\hline 1 & Kurang Baik & & 16 & 24,60 \\
\hline 2 & Baik & & 49 & 75,40 \\
\hline & & Total & 65 & 100,00 \\
\hline
\end{tabular}

Berdasarkan Tabel 3 diperoleh informasi bahwa mayoritas bidan $(75,40 \%)$ memiliki kesadaran sosial yang baik. Bidan telah memiliki kompetensi empat orientasi pelayanan dan kesadaran organisasi yang baik. Hal seperti ini dibutuhkan oleh bidan yang bertugas di Poli KIA Puskesmas dalam rangka 
pemeriksaan kandungan ibu hamil, hamil, maka diharapkan semakin khususnya dalam proses pemberian tablet meningkatnya kinerja bidan sehingga Fe. Sedangkan untuk bidan dengan kesadaran sosial yang kurang baik, dapat segera meningkatkan kemampuan utamanya kompetensi empati yang pada hasil sebelumnya menunjukkan ketidakmampuan beberapa bidan dalam merasakan masalah yang dialami ibu hamil.

Dengan semakin terasah kesadaran sosial bidan serta mampu memberikan bentuk kepedulian yang baik kepada ibu berdampak pada kepuasan bagi para ibu hamil. Hal ini didukung dengan hasil penelitian yang mengungkapkan bahwa kepedulian sosial memiliki hubungan yang kuat dan positif pada kepuasan kerja ${ }^{18}$.

\section{Usia denganKesadaran Sosial Bidan}

Keterkaitan antara usia bidan dengan kesadaran sosial dapat dilihat pada Tabel 4. berikut ini.

Tabel 4. Tabulasi Silang antara Usia Bidan dengan Kesadaran Sosial Bidan di Puskesmas Kota Surabaya

\begin{tabular}{|c|c|c|c|c|c|c|c|}
\hline \multirow{3}{*}{\multicolumn{2}{|c|}{ No. Usia Bidan }} & \multicolumn{4}{|c|}{ Kesadaran Sosial } & \multirow{2}{*}{\multicolumn{2}{|c|}{ Total }} \\
\hline & & \multicolumn{2}{|c|}{ Kurang } & \multicolumn{2}{|c|}{ Baik } & & \\
\hline & & $\mathbf{n}$ & $\%$ & $\mathbf{n}$ & $\%$ & $\mathbf{n}$ & $\%$ \\
\hline 1 & $\leq 25$ tahun & 9 & 100,00 & 0 & 0,00 & 9 & 100,00 \\
\hline 2 & $26-35$ tahun & 4 & 12,10 & 29 & 87,90 & 33 & 100,00 \\
\hline 3 & $36-45$ tahun & 1 & 10,00 & 9 & 90,00 & 10 & 100,00 \\
\hline \multirow[t]{2}{*}{4} & $46-55$ tahun & 2 & 15,40 & 11 & 84,60 & 13 & 100,00 \\
\hline & Total & 16 & 24,60 & 49 & 75,40 & 65 & 100,00 \\
\hline
\end{tabular}

Berdasarkan Tabel 4. didapatkan informasi bahwa bidan yang memasuki umur 26-35 tahun maupun 36-45 tahun cenderung memiliki kesadaran sosial yang baik dengan persentase masing-masing sebesar $87,90 \%$ dan 90,00\%. Hal ini berperan dalam pelaksanaan layanan pemberian tablet Fe pada ibu hamil karena butuh kesadaran sosial yang tinggi. Bidan yang masih muda cenderung belum mempunyai bekal kesadaran sosial yang baik jika dibandingkan dengan bidan yang sudah berumur. Bidan yang berumur sudah mampu memiliki bekal kesadaran sosial yang lebih baik karena telah memiliki pengalaman dalam berinteraksi dengan dunia sosial.

\section{Lama Kerja Bidan denganKesadaran Sosial Bidan}

Keterkaitan antara lama kerja bidan dengan kesadaran sosial dapat dilihat pada Tabel 5.berikut ini.

Tabel 5. Tabulasi Silang antara Lama Kerja Bidan dengan Kesadaran Sosial Bidan di Puskesmas Kota Surabaya

\begin{tabular}{|c|c|c|c|c|c|c|c|}
\hline \multirow{3}{*}{\multicolumn{2}{|c|}{ No. Lama Kerja Bidan }} & \multicolumn{4}{|c|}{ Kesadaran Sosial } & \multirow{2}{*}{\multicolumn{2}{|c|}{ Total }} \\
\hline & & \multicolumn{2}{|c|}{ Kurang } & \multicolumn{2}{|c|}{ Baik } & & \\
\hline & & $\mathbf{n}$ & $\%$ & $\mathbf{n}$ & $\%$ & $\mathbf{n}$ & $\%$ \\
\hline 1 & Dibawah 6 tahun & 12 & 46,20 & 14 & 53,80 & 26 & 100,00 \\
\hline 2 & $6-10$ tahun & 2 & 15,40 & 11 & 84,60 & 13 & 100,00 \\
\hline \multirow[t]{2}{*}{3} & Diatas 10 tahun & 2 & 7,70 & 24 & 92,30 & 26 & 100,00 \\
\hline & Total & 16 & 24,60 & 49 & 75,40 & 65 & 100,00 \\
\hline
\end{tabular}


Berdasarkan Tabel 5. diperoleh informasi bahwa bidan yang memiliki pengalaman kerja lama cenderung memiliki kesadaran sosial yang lebih baik. Bidan dengan lama kerja diatas 10 tahun mayoritas memiliki kesadaran sosial yang baik $(92,30 \%)$. Semakin lama bidan bekerja maka semakin terbiasa dan mudah melakukan interaksi dengan ibu hamil.

Hal ini didasari bahwa bidan dengan pengalaman lebih dalam melayani ibu hamil akan tumbuh dalam dirinya kesadaran sosial yang semakin baik. Kebiasaan yang bidan lakukan akan menjadi sebuah pembelajaran untuk dapat meningkatkan kesadaran sosial yang dimiliki.

\section{Pengaruh Usia dan Lama Kerja Bidan terhadapKesadaran Sosial Bidan}

Analisis pengaruh usia dan lama kerja bidan terhadap kesadaran sosial bidan dilakukan dengan menggunakan uji Regresi Logistik Ordinal. Detail pengaruh usia dan lama kerja bidan terhadap kesadaran sosial bidan di Puskesmas, dapat dilihat pada Tabel 6 . berikut ini.

Tabel 6. Pengaruh Usia dan Lama Kerja Bidan terhadap Kesadaran Sosial Bidan di Puskesmas Kota Surabaya

\begin{tabular}{|c|c|c|c|}
\hline Variabel Independent & $\mathrm{P}$ & OR & Keterangan \\
\hline \multicolumn{4}{|l|}{ Usia Bidan } \\
\hline 46-55tahun & $0,001(<0,05)$ & 5,00 & Berpengaruh signifikan \\
\hline 36-45tahun & $0,001(<0,05)$ & 14,06 & Berpengaruh signifikan \\
\hline 17-25tahun & & & Pembanding \\
\hline \multicolumn{4}{|l|}{ Lama Kerja } \\
\hline$>10$ tahun & $0,021(<0,05)$ & 0,06 & Berpengaruh signifikan \\
\hline 6-10tahun & $0,067(>0,05)$ & & Berpengaruh tidak signifikan \\
\hline$<6$ tahun & & & Pembanding \\
\hline
\end{tabular}

Berdasarkan Tabel 6. dapat diinformasikan bahwa usia bidan dengan kategori 46-55 tahun berpengaruh signifikan terhadap kesadaran sosial yang dimiliki bidan untuk menjadi lebih baik 5 kali jika dibandingkan dengan umur bidan dengan kategori 17-25 tahun. Demikian halnya dengan umur bidan dengan kategori 36-45 tahun berhubungan signifikan dengan kesadaran sosial yang dimiliki bidan untuk menjadi lebih baik 14 kali jika dibandingkan dengan umur bidan dengan kategori 17-25 tahun. Sedangkan kategori umur lainnya berpengaruh tidak signifikan terhadap kesadaran sosial bidan di Puskesmas.

Usia yang lebih tua memiliki hubungan dengan kesadaran sosial yang dimiliki bidan. Bidan yang lebih tua cenderung memiliki kesadaran sosial yang baik. Hal ini berperan dalam pelaksanaan layanan pemberian tablet $\mathrm{Fe}$ pada ibu hamil karena membutuhkan penerapan kesadaran sosial yang tinggi. Kesadaran sosial merupakan bagian yang tidak terpisahkan didalam kehidupan bermasyarakat.Hal ini tidak saja menyangkut aktivitas sosialisasi dan kepercayaan diri, namun juga mengarah pada sikap-sikap yang menunjukkan kepedulian terhadap lingkungan sekitarnya seperti sikap saling menghormati, toleransi, dan sebagainya.

Goleman $^{9}$ mengatakan bahwa kesadaran sosial yang dimiliki bidan tumbuh dan berkembang sejalan dengan perkembangan fisik dan mental.Dengan 
demikian, kesadaran sosial bidan cenderung kurang saat masih dalam rentang umur kurang dari 25 tahun.Bidan yang masih muda cenderung belum mempunyai bekal kesadaran sosial yang baik jika dibandingkan dengan bidan yang sudah berumur lebih tua.Bidan yang berumur lebih tua mampu memiliki bekal kesadaran sosial yang lebih baik karena telah memiliki pengalaman dalam berinteraksi dengan dunia sosial.

Lama kerja bidan dengan kategori > 6 tahun berpengaruh signifikan dengan kesadaran sosial yang dimiliki bidan untuk menjadi lebih baik 0,06 kali jika dibandingkan dengan lama kerja bidan dengan kategori < 6 tahun. Sedangkan kategori lama kerja lainnya berpengaruh tidak signifikan dengan kesadaran sosial yang dimiliki bidan di Puskesmas.

Umumnya bidan dengan pengalaman kerja yang lebih lama cenderung memiliki kesadaran sosial yang lebih baik. Dalam penelitian ini, lama kerja diatas 10 tahun memiliki hubungan dengan kesadaran sosial yang dimiliki bidan daripada mereka yang lama kerjanya dibawah 10 tahun. Hal ini didasari bahwa bidan dengan pengalaman lebih dalam melayani ibu hamil akan tumbuh dalam dirinya kesadaran sosial yang semakin baik.Hal ini sejalan dengan teori Goleman ${ }^{4}$ yang menyatakan bahwa kesadaran sosial tumbuh dan berkembang sejalan semakin dipupuk dan diperkuatnya diri dalam waktu yang cukup.Nugroho Utomo menyampaikan bahwa terdapat hubungan yang signifikan antara masa kerja atau lama kerja dengan tingkat kesadaran ${ }^{16}$. Menurut Notoatmodjo, masa kerja merupakan salah satu faktor pada karakteristik tenaga kerja yang membentuk perilaku.Semakin lama masa kerja tenaga kerja akan membuat tenaga kerja lebih mengenal kondisi lingkungantempatkerja ${ }^{13}$. Masakerjadapatmemberikan pengaruhpositifpadakinerjaapabila dengansemakinlamanyamasakerja personalsemakinberpengalaman dalammelaksanakantugasya.Namun demikian,jugadapatmemberikan pengaruhnegatifapabiladengan semakinlamamasakerjaakantimbul perasaanterbiasadengankeadaandan menyepelekan pekerjaan ${ }^{17}$.

Oleh sebab itu, dapat menjadi pertimbangan bila ingin menempatkan seorang petugas yang akan bertanggung jawab dalam hal pemberian pelayanan pada masyarakat untuk lebih memperhatikan lama masa kerja atau pengalaman kerja yang dimiliki oleh bidan karena dapat berkaitan dengan tingkat kesadaran sosial yang dimiliki.

\section{SIMPULAN DAN SARAN}

\section{Simpulan}

1. Sebagian besar bidan di Puskesmas termasuk dalam kategori umur 26-35 tahun dan merupakan kelompok pekerja produktif. Lama kerja bidan umumnya lebih dari 10 tahun mengabdi dalam melayani Ibu hamil di Puskesmas.

2. Mayoritas bidan di Puskesmas memiliki kesadaran sosial yang baik.

3. Bidan yang usianya lebih matang cenderung memiliki kesadaran sosial yang baik.

4. Bidan yang memiliki pengalaman kerja lebih lama cenderung memiliki tingkat kesadaran sosial yang lebih baik.

\section{Saran}

1. Bidan harus melatih diri mengenali perasaan sendiri, mencoba memandang masalah dari sudut pandang orang lain, berusaha menjadi pendengar yang baik dan melatih berkorban untuk kepentingan orang lain terutama ibu hamil.

2. Bidan harus mampu menjalin hubungan baik dengan ibu hamil, menciptakan 
kedekatan secara personal dan memupuk rasa kekeluargaan.

\section{DAFTAR RUJUKAN}

1] Depkes, 2007. Profil Kesehatan Indonesia Years 2006. Jakarta: Departemen Kesehatan RepublikIndonesia.

2] Kemenkes, 2010. Rencana Strategis (Renstra) Kementrian Kesehatan Tahun 2010-2014. Jakarta: Kementerian Kesehatan Republik Indonesia.

3] Triyani, S dan Purbowati, N. 2016. Kepatuhan Konsumsi Tablet $\mathrm{Fe}$ Dalam MencegahAnemi Gizi Besi Pada Ibu Hamil Di Wilayah PuskesmasKecamatan Jakarta Pusat.Jurnal Ilmu dan Teknologi Kesehatan.Vol.3 No.2: 215-229.

4] Depkes, 2007. Survei Kesehatan Rumah Tangga (SKRT) 2007. Jakarta: Badan Penelitian dan Pengembangan Kesehatan.

5] Goleman, D., 1997. Emotional Intelligence. Jakarta: PT. Gramedia Pustaka Utama.

6] Sugiyono, 2009. Metode Penelitian Kuantitatif, Kualitatif dan $R \& D$. Bandung: Alfabeta.

7] Nitisemito, A. S., 2000. Manajemen Personalia: Manajemen Sumber Daya Manusia. 3 ed. Jakarta: Ghalia Indonesia.

8] Erawan, I Nyoman. 1984. Pariwisata dan Pembangunan Ekonomi: Bali sebagaiKasus. Denpasar: Upada Sastra.

9] Ranupendjaja, H. \& Saud, H., 2002. Manajemen Personalia. Yogyakarta: BPFE UGM.
10] Goleman, D., 1999. Working with Emotional Intelligence: Kecerdasan Emosi untuk Mencapai Puncak Prestasi. Jakarta: Gramedia PustakaUtama.

11] Kemenkes RI. 2010. Pedoman Penanggulangan Anemia GiziuntukRemajaPutridanWanitaUsia Subur. Jakarta: Depkes RI.

12] De Maeyer, E.M. 2013. Pencegahan danPengawasanAnemiaDefisiensiBesi. Jakarta:PenerbitWidyaMedika.

13] Notoadmodjo, S.2012. PengantarPerilakuKesehatandanIlmu Perilaku. Jakarta:PenerbitRinekaCipta.

14] Handayani, L. 2013. Peran Petugas Kesehatan dan Kepatuhan Ibu Hamil Mengkonsumsi Tablet Besi.Kesmas.Vol.7 No.2: 55-112.

15] IBI. 2005. Standar Pelayanan Kebidanan. Cetakan ke-5.Jakarta: Pengurus Pusat IBI.

16] Utomo, N. 2015. Hubungan Tingkat Pengetahuan Risiko Penyakit Akibat Kerja dengan Kesadaran Pemakaian Masker pada Pekerja Bagian Operator Jahit CV. Maju Abadi Garment Sukoharjo. Surakarta: UMS.

17] Tulus, MA. 2002. Manajemen Sumber Daya Manusia. Jakarta: Balai Pustaka.

18] Masrek, M. N., Osman, M. A. F., Khamis, Y. \& Paiman, M. J., 2014. The Relationship Between Emotional Intelligence and Job Satisfaction: The Case of Malaysian Information Technology Professionals. International Journal of Multidisciplinary and Current Research, Volume 2, pp. 1106-1111. 